\title{
Priorities for social science and humanities research on the challenges of moving beyond animal-based food systems
}

Increasingly high-profile research is being undertaken into the socio-environmental challenges associated with the over-production and consumption of food from animals. Transforming food systems to mitigate climate change and hidden hunger, ensure food security and good health all point to reducing animal-based foods as a key lever. Moving beyond animal-based food systems is a societal grand challenge requiring coordinated international research by the social sciences and humanities. A 'selective openness' to this range of disciplines has been observed within multi-discipline research programmes designed to address societal grand challenges including those concerned with the sustainability of food systems, inhibiting the impact of social sciences and humanities. Further, existing research on animal-based foods within these disciplines is largely dispersed and focused on particular parts of food systems. Inspired by the 'Sutherland Method' this paper discusses the results of an iterative research prioritisation process carried out to enhance capacity, mutual understanding and impact amongst European social sciences and humanities researchers. The process produced 15 research questions from an initial list of 100 and classified under the following five themes: (1) debating and visioning food from animals; (2) transforming agricultural spaces; (3) framing animals as food; (4) eating practices and identities; and (5) governing transitions beyond animal-based food systems. These themes provide an important means of making connections between research questions that invite and steer research on key challenges in moving beyond animal-based food systems. The themes also propose loci for future transdisciplinary research programmes that join researchers from the natural sciences, social sciences, and humanities and stakeholders from beyond academia to develop cooperative research and implementation initiatives. The experiences gained from the prioritisation process draw attention to the value of spending time to discuss and collaboratively steer research enquiry into emergent and controversial matters of concern. Fundamental, ethical questions around the continuation or complete cessation of the use of animals for food was a key tension. The positioning of research towards these questions affects not only the framing of the research area but also the partners with whom the research can be carried out and for whom it may be of benefit.

\footnotetext{
\#A list of authors and their affiliations appears at the end of the paper.
} 


\section{Introduction}

ncreasingly high-profile research is being undertaken into the socio-environmental challenges associated with the overproduction and consumption of food from animals, including in particular climate change, ill-health and increased hidden hunger ${ }^{1}$. In the last 50 years the global net consumption of meat has quadrupled, as the global population is on average eating twice as much meat as their grandparents and are double the number of people (Weis, 2013). The rapid intensification of animal production that underpins the rise in meat consumption has had a vast impact on the air, land and water of the planet, in the form of not only emissions from farm animals, but also emissions from feed cultivation, land and soil degradation, and water pollution (Godfray et al., 2018; IPCC, 2019; Springmann et al., 2018; Willett et al., 2019). The negative health effects of consuming large quantities of red and processed meat and dairy are also well known, although contested (Brown, 2019; Swinburn et al., 2019), while risks of food poisoning and antibiotic resistance are amplified with intensified livestock production (O'Neill, 2015). Attention has been drawn to the need for a significant reduction in the production and consumption of food from animals and a concomitant increase in plant-based eating (Willett et al., 2019). This can be viewed as an instantiation of a societal grand challenge as it concerns the socio-economic system as a whole and thus requires system transformation (Kuhlmann and Rip, 2014; Schot and Steinmueller, 2016). Such challenges, and the attendant multi-faceted processes of change required to address them, involve numerous actors with varied perspectives on the nature of the problem to be solved, and how it may be resolved. Researchers are one diverse group generating the knowledge required to formulate an effective societal response. This paper contributes to this process by presenting key research questions in relation to a move beyond animal-based food systems as identified by European academics in the social sciences and humanities.

Addressing societal grand challenges can be viewed as a challenge in itself, requiring a willingness to explore new combinations of existing and novel approaches to knowledge production (Kuhlmann and Rip, 2018) as reflected in the frequent use of multi-, inter- and trans-disciplinary research programmes that bring together researchers from the natural sciences, social sciences and humanities as well as non-academic stakeholders (Efstathiou, 2016). However, it has been shown that this process can narrowly position or even mis-conceive the contribution of social sciences and humanities (Shove, 2010; Castree et al., 2014; Felt, 2014; Balmer et al., 2015), leaving such research programmes only 'selectively open' to the breadth of competencies and insights provided by these disciplines (Morris et al., 2019). This selective openness may impoverish, if not inhibit research impact. One practical response is to make spaces in which social sciences and humanities scholars have the freedom to collaboratively devise research agendas that reflect the full spectrum of expertise, capabilities and analytical perspectives in these disciplines. In this article we report the creation and outcome of one such space in which academic leaders within the social sciences and humanities came together to address future research priorities for moving beyond animal-based food systems. We acknowledge the partial nature of this exercise, and the situatedness of this set of knowers (Haraway, 1988), and offer these identified priorities as an important stage in a wider dialogue.

In undertaking this task the article draws attention to research into changing patterns of consumption and production of food from animals that is carried out across multiple fields within social science and the humanities, some of which is of quite longstanding. Prominent is consumption-oriented work on the motivations and behaviours, practices, and identities of becoming vegan or vegetarian (e.g. Aavik, 2019a; Beardsworth and Keil, 1992; de Boer et al., 2017; Doyle, 2016; Fiddes, 1994; Greenebaum and Dexter, 2018; Morris and Kirwan, 2006; Rosenfeld and Burrow, 2017; Ruby, 2011; Smart, 2004; Twine, 2014; Potts and Parry, 2010) and various institutional dimensions of veganism and vegetarianism (e.g. Aavik, 2019b; Cole and Morgan, 2011). Another strand of research highlights the structural and ideological reproduction of animal-based food systems, which concomitantly inhibit transitions to plant-based alternatives (e.g. Almiron, 2016; Cole and Stewart, 2014; Nibert, 2016; Twine, 2010). Critical analysis of current regimes of meat provisioning (e.g. Emel and Neo, 2015; Fitzgerald and Taylor, 2015; Fourat and Lepiller, 2017; Weis, 2007, 2013) has been accompanied by work on the governance and politics of transitions towards lowering meat production and consumption (e.g. de Bakker and Dagevos, 2012; de Boer et al., 2014; Chiles, 2016; Garnett et al., 2015; Laestadius et al., 2014; Kaljonen et al., 2019, 2020; Morris et al., 2014; Morris, 2019; Singer, 2016; Vinnari and Vinnari, 2014) as well as work on transforming food practices that make meat central to the Western plate and beyond (cf. Shove et al., 2012; Potts, 2016; Efstathiou et al., 2019; Hansen and Jakobsen, 2020). The cultural and moral economies of alternative proteins (Driessen and Korthals, 2012; Mylan et al., 2019; Sexton, 2018; Sexton et al., 2019; Stephens et al., 2019) and the consumption of these novel products (e.g. Elzerman et al., 2011; Hoek et al., 2004; Vinnari and Tapio, 2009) has also attracted research attention (Lonkila and Kaljonen, 2021).

This rich body of scholarship examines different aspects of past, current and future food systems as these concern animalbased foods. However, it is research that is dispersed in many ways, dealing with particular aspects of food production, consumption or provision. This runs the risk of social science and humanities perspectives not being given due attention at a time when food policy debates and accompanying research programmes are paying increasing interest to more holistic, systembased approaches when seeking to build more sustainable food systems. Recent examples include the Farm to Fork Strategy by the European Commission (EC, 2020) and the food system approaches promoted by the Food and Agriculture Organisation (FAO) (2018; see also IPES food, 2015; HLPE, 2017) ${ }^{2}$. In addressing the societal grand challenge of moving beyond animalbased food systems the research prioritisation exercise reported in this paper was designed to help steer and stimulate further research in the social sciences and humanities in ways that might be more influential in transforming food policy and associated research funding agendas based on a food system perspective. It was inspired by the 'Sutherland Method' (Sutherland et al., 2009,2011 ), a form of deliberative research prioritisation that has gained more attention in recent years and which aims to bring together researchers and stakeholders to discuss and create a common understanding of knowledge needs in emergent areas of enquiry or areas of particularly pressing policy need. Such research prioritisation exercises are valuable in creating momentum around and reflection upon societally relevant research needs. As adapted for our purposes we engaged social scientists and humanities scholars with an aim to build mutual understanding, research capacity and impact amongst peers in this emergent but still largely fragmented area of research interest. The collaborative effort was initiated by two researchers, one from the UK, the other from Finland, who have also taken the lead in preparing this article. The exercise included several iteration rounds amongst researchers active in the field.

In what follows we first detail the method used. We continue by discussing how the participants defined emergent areas of research interest and present key research questions for the social 
sciences and humanities. The conclusions of the process draw attention to fundamental tensions at the heart of the subject matter that should be given more sustained consideration in future research, notably whether or not animals should be farmed for food, and the need to extend the exercise to engage a range of other researchers and non-academic actors including those whose livelihoods currently depend on farming animals for food.

\section{Research prioritisation exercise}

The Sutherland Method has come to prominence over the last decade as a participatory approach, engaging both researchers and non-academic stakeholders, to identifying and prioritising research questions in particular fields of enquiry including those which address societal grand challenges such as biodiversity loss, food supply and security (Sutherland et al., 2009, 2011, 2012; Pretty et al., 2010; Ingram et al., 2013). Named after William Sutherland, who has played a leading role in developing and reporting the method, it has subsequently been utilised successfully in fields as diverse as animal research (Davies et al., 2016), legislative science advice (Akerlof et al., 2019) and the human microbiome (Greenhough et al., 2020). A number of methods exist to elicit expert views on matters of concern, e.g. the Delphi method, the James Lind Alliance (JLA) approach used in medical research (e.g. Hasson et al., 2000; The James Lind Alliance, 2020), and systematic literature reviews that map research findings and gaps in a certain field of enquiry (Petticrew and Roberts, 2006). We chose the Sutherland Method because it is specifically designed to support the collaborative development of research agendas through a combination of survey and face-to-face interactions between relatively small groups of participants.

In designing the distinct phases of our research prioritisation exercise we were guided by earlier exercises but translated them to our needs in working with social sciences and humanities researchers. It is acknowledged that the inclusion only of researchers in this process, albeit academic leaders in the research area, is a departure from the Sutherland Method and those of the Delphi and JLA methods as originally conceived. However, this is an appropriate, initial stage of collaborative research prioritisation within the context of a dispersed area of enquiry. As explained in the section "Introduction", the deliberate focus on the social sciences and humanities provided a dedicated space for these disciplines to frame research questions without feeling constrained to accommodate the concerns of other disciplines and agendas, thereby helping to create research capacity but also build coordination amongst scholars to support system-wide change. In addition, the focus is justified as a means of fostering dialogue amongst scholars with very different opinions of and ideological positions on the issue at stake, not to mention radically divergent methodological and epistemological commitments, in advance of engaging other disciplines and stakeholders.

The research prioritisation exercise was carried out in the following six stages: (1) online survey to gather information from the participating researchers; (2) first deliberative workshop held in Nottingham, UK; (3) further rewording of the priority questions and identification of research themes; (4) second deliberative workshop held in Tampere, Finland; (5) further refinement of the research questions and; (6) collaborative writing up (Table 1).

The invitation to the first stage Online Survey targeted social science and humanities researchers carrying out research on this topic. The lead authors identified the researchers through their professional networks, published literature and by snowballing, i.e. professional contacts suggesting other suitable participants. The majority of those who agreed to participate were from the social sciences in particular sociology and geography. Participants also work in human-animal studies, including critical animal studies, and in cultural studies, science and technology studies and food studies. Researchers from different career stages participated, including post-doctoral researchers, those from earlymid career dominated and the majority were female.

The participants were asked to complete an online survey and to list at least one and no more than ten research questions on 'de-animalising the food system' ${ }^{3}$ from the perspective of the social sciences and humanities. Participants were encouraged to consult colleagues both within and beyond academia in formulating their questions. The main criterion given for research questions were that they must be amenable to study by social science and humanities concepts and methods but they could be of an interdisciplinary nature providing the question includesd a dimension that is amenable to social science and humanities concepts and methods (Sutherland et al., 2011). In addition to submitting research questions, participants were also encouraged to respond to the following invitation to reflect on the research topic: "We recognise that the phrase "de-animalising the food system' is simultaneously provocative and rather awkward. How might we refer more effectively to or define the emergent area of research in which we are all working?". Nineteen comments of varying lengths and levels of detail were submitted, and these were coded to identify cross-cutting themes.

The survey produced a total of 100 research questions. The lead researchers divided the questions into three broad themes to help manage their subsequent discussion: (1) eating and consumption; (2) food system transformation; and (3) governance and politics. Each theme consisted of around 30 questions. None of the questions were re-written or excluded at this point and all of them were circulated to participants prior to the first workshop.

Stage two involved the deliberation of the initial list of 100 questions in a full-day workshop in Nottingham, UK, 2 months following stage one. Participants were assigned by the lead researchers, according to their known research interests and expertise, to work with one of the three themes in a group of 5-7 participants. Each member of the group was asked to score each question from 1-10 according to the question's degree of importance (where 1 was relatively less important and 10 was relatively more important). These scores were then entered into a spreadsheet managed by the group facilitator and projected live onto a screen. Once all group members' scores had been entered a final score was calculated for each of the questions. The ten questions that received the highest scores were focused upon in the subsequent discussion within each of the thematic groups. Group members were encouraged to reword questions and to amalgamate similar questions at this stage. The group's facilitator also kept notes on the discussion held. These notes were recorded in a separate column of the projected spreadsheet so that group members could amend them. At the end of this process each group reported their scores and key points of their discussion back to the other groups. In the workshop, the participants also provided short presentations on their own research and a collective discussion on the definition of the area of research interest was started.

In the third stage of the prioritisation exercise, the lead authors worked on the 10 questions that achieved the highest scores in each of the three thematic groups, to further reword and clarify individual questions or amalgamate them into fewer questions. At this stage the analysis concentrated on highlighting interlinkages between individual questions enabling a further regrouping of questions for discussion at the second workshop. The lead authors also compiled a draft text on the nature and scope of the area of research interest based on the suggestions provided by the participants in the survey and the first workshop (stages 1 and 2). The finalised version of this text is presented in the next section of the article. 
Table 1 The six stages of the research prioritisation process.

\begin{tabular}{|c|c|c|}
\hline Stages & Tasks & Number of researc \\
\hline $\begin{array}{l}\text { 3. Rewording of priority research questions and } \\
\text { classification of research themes (July, } \\
\text { August 2019) }\end{array}$ & $\begin{array}{l}\text { Rewording and clarification of the prioritised } \\
\text { research questions. } \\
\text { Drafting a text on the definition of the area of } \\
\text { research interest. }\end{array}$ & Two lead authors \\
\hline $\begin{array}{l}\text { 4. Deliberative workshop in Finland } \\
\text { (September 2019) }\end{array}$ & $\begin{array}{l}\text { Short presentations of the research history of the } \\
\text { participants. Further iteration of the priority } \\
\text { research questions. } \\
\text { Discussion on the draft text describing the area of } \\
\text { research interest. }\end{array}$ & 16 researchers \\
\hline 5. Refinement of research questions and themes & $\begin{array}{l}\text { Further refinement of the prioritised research } \\
\text { questions and research themes. }\end{array}$ & Two lead authors \\
\hline 6. Collaborative writing & $\begin{array}{l}\text { Two lead authors produced the first manuscript to } \\
\text { which the other authors contributed. } \\
\text { The revisions to the text were made by the two } \\
\text { lead authors, and then discussed, refined, and } \\
\text { approved by the others. }\end{array}$ & 30 researchers \\
\hline
\end{tabular}

In the fourth stage, the questions and the text defining the area of research interest were subject to further deliberation in a half day workshop held in Tampere, Finland. This workshop was one of several pre-congress workshops organised in association with the conference of the European Society for Agriculture and Food Ethics (EurSafe). The invitation to the workshop was sent to all conference participants. In addition, several Finnish scholars were invited directly to secure a breadth of participation. In total 16 researchers took part in the workshop. ${ }^{4}$ Participants received in advance the list of priority research questions and the commentary on the nature and scope of the field of research enquiry developed during stage three of the process. The academic profile of participants was slightly different to the first workshop which reflected in part the ethics focus of the conference, attracting both humanities and social science scholars including from philosophy, political science, sociology, geography and ecological economics. This had a notable impact on the nature and focus of the discussion. For example, participants were much more critical of the 'de-animalising' framing in part because this has a negative meaning for some food and animal ethicists. Like the first workshop, all career stages were represented, and most participants were female. Participants were invited to discuss and make suggestions for developing the draft text, developed in stage 3 , on defining the research area. They were also asked to discuss each of the questions in detail, e.g. to make suggestions about rewording and other forms of editing and encouraged to identify gaps in the research questions. In the Tampere workshop, all participants discussed the questions together instead of dividing into smaller groups.

Subsequent to the workshop, in the fifth stage, the lead authors undertook a further refinement and consolidation of the question list. For example, several questions were reworked to enhance their clarity and cogency and to change their emphasis from future situations to the study of present actions and interventions. In the sixth stage, the lead authors circulated a draft text of this article, via a shared document, to all participants. They revised and edited the text and provided references to additional literature allowing for a collaborative writing process between 30 authors.

In terms of research ethics, the research project of which this exercise comprised one dimension has passed institutional ethical review. No personal nor sensitive information was collected during the research prioritisation exercise. All of those involved participated on an informed and voluntary basis with the possibility of becoming a co-author and thereby further 'owning' the results.

\section{Defining an emerging area of research interest}

In both the Nottingham and Tampere workshops we discussed how research that is beginning to coalesce around a move beyond animal-based food systems could be referred to, defined and conceptualised. In the invitation to the exercise, we entitled the area of enquiry as 'de-animalising the food system' which, following discussion amongst participating researchers, led to the adoption of the more dynamic wording of 'beyond animal-based food systems'. We elaborate this decision below and discuss how participants made sense of the nature and scope of research in this area, including its complexity and contention, the geographical locations of empirical research, and the role for interand trans-disciplinary research approaches.

From 'de-animalising the food system' to 'beyond animalbased food systems'. The initial framing of 'de-animalising the food system' is derived from the idea of the animalising of food systems (Fourat and Lepiller, 2017) or meatification (Weis, $2007,2015)$ of diets, i.e. the significant increase in the number of animals used in food production globally and associated with the intensification of production systems. If 'animalising' the food system means using more animals and more intensively then it is 
reasonable to conjecture that 'de-animalising' means, at the very least, using animals less and more extensively but it can also encompass the position that animals should not be used for human benefit at all. Although by no means accepted as an unproblematic framing of the issues of interest, the participants of the first workshop worked with the 'de-animalising' framing as the basis of the question identification. At the second workshop participants made use of the forum to discuss and critique the framing, including the use of the term 'animal' rather than 'nonhuman animal' (see endnote one). There were several elements to this critique. First, in some domains of debate, such as animal ethics, 'de-animalising' refers to a deliberate undermining of the essence and quality of existence of the animal e.g. through breeding to reduce the experience of suffering in intensive production system (Sandoe et al., 1999) and might convey the loss or invisibilising of the animal by the cutting up of animal bodies in slaughtering (Vialles, 1994; Bjørkdahl and Syse, 2016). Second, it was argued that there are many food systems rather than a single system. Third, the notion of 're-animalising' was proposed as an alternative to 'de-animalising', a framing that highlights more prominently the agency of animals in food systems and the need for more research on the ways in which animals are framed, used, exploited or cared for in food systems. These discussions led the two lead authors to change the title of the process we are describing here to 'beyond animal-based food systems' allowing the various roles of animals to be considered.

Nature and scope of the research area. Participants made suggestions about the nature and scope of the research area acknowledging that what is being addressed is a politically and ethically charged and contentious set of issues particularly for stakeholders whose livelihoods depend on animals existing in food systems but also for practices and identities centred on consuming food from animals. Yet these urgent issues cannot be ignored, requiring immediate further research, policy attention and practical action.

The nature of research in this area concerns the environmental, social, economic, cultural and ethical impacts and couplings of the production and consumption of animals and animal-derived materials in food systems. Terms such as 'exploitative' and 'violent' were employed by some participants to describe these impacts. Others underlined the more positive tone in maintaining an environmentally sustainable livelihood for humans and animals involved in food production. In approaching these matters, participants emphasised a need for holistic and systemic perspectives. Such perspectives recognise the multiple domains and actors implicated in moving beyond animal-based food systems including the intensely personal aspects of eating-or not eating-food from animals and the variable health outcomes of these positions, to the food from animals industries and the complex of resources, materialities, politics and power that these engage.

In elaborating as well as seeking to clarify what is being studied within this area of research, an important fault-line appeared. For some contributors, research should be concerned with the complete removal of animals and animal products in the food chain i.e. the elimination of dependence on animal exploitation from the food system, a move that simultaneously entails the study and promotion of the transition towards plant-based diets and veganism ${ }^{5}$. In contrast to a construction of the research area as focusing on veganic food systems, a more modest construction is concerned with the significant reduction in animal use at all stages and across all domains of the food system, including the removal of harmful animal husbandry systems. This perspective problematizes the over-production and consumption of food from animals without specifying that all animal production and consumption needs to be eliminated, i.e. it does not unsettle, in a fundamental way, normative human-animal relations. Rather, what is implied instead is a significant scaling back and deintensification of animal agriculture and food production. Workshop discussion further explored the question of 'how big should the reduction of livestock animals in food systems be?' but without reaching a consensus. It was also emphasised that this is not only a matter for the social sciences and humanities, extending to various disciplines in the natural sciences as well as to society more broadly.

Whether and how these different positions should co-exist within this research area requires further consideration. One suggestion is that rather than positing opposing pathways beyond animal-based food systems a more productive way forward is to identify a continuum of pathways, where animal-human relations are considered as part of a more holistic understanding of sustainable food systems. Whatever endpoint is envisaged by individual scholars, there was agreement that the research area is interested in understanding, disrupting and reconfiguring normalised practices, from farms to fork, and from worth to waste. In turn this implies far-reaching systemic changes, extending well beyond the singular problem of 'de-animalisation'. The normative character of research in this area was also acknowledged and calls were made for this to be constantly interrogated and critically evaluated.

The geographical location of research. The geographical location of research was not consistently specified across the definitions provided. However, some differences were evident. As such, for some research in this area is concerned, first and foremost, with "the West" or the Global North reflecting the excessive degree to which food systems have been meatified in this context (e.g. Allievi et al., 2015; Weis, 2015) but also, perhaps, the European background of most participants. Others asserted that research on going beyond animal-based food systems needs to take place across a range of food cultures including high-, middle- and low-income countries, not least because food systems are so entangled globally (Winders and Ransom, 2019). The participants called for more research on the Global South but also for engagement of researchers from minority groups in defining the research area, enabling decolonial and indigenous perspectives. They also recognised that moving beyond animal-based food systems might require totally different premises in different countries, not least because of regional differences and specificities in meat consumption and production.

A role for multiple disciplines and trans-disciplinarity. There was broad agreement that the research area engages multiple disciplines, both within the social sciences and humanities but also the natural, agricultural, food and nutrition sciences and there may be value in multi and interdisciplinary working. More specifically it was pointed out that the social sciences and humanities are vital in bringing critical perspectives to the more quantitative approaches of the natural and agricultural sciences. Less attention was given to the range of perspectives and approaches that might be mobilised by social science and humanities scholars working within the field although it was suggested that research is likely to involve both theoretical as well as more empirical and practically oriented work. The need to engage stakeholders outside the academy in the production of knowledge was also highlighted, demonstrating the trans-disciplinary character of the research area. 


\section{Prioritised research questions}

The research prioritisation exercise produced a list of 15 research questions to which social sciences and humanities should pay more attention in future. They are presented under the following themes: (1) debating and visioning food from animals; (2) transforming agricultural spaces; (3) framing animals as food; (4) eating practices and identities; and (5) governing transitions beyond animal-based food systems. Some of the questions might best be used to guide large research programmes while others are more immediately operationalised in specific empirical contexts and as such likely to offer insight into particular aspects of food systems transformation. Unless specified, the questions can apply to any number of country contexts and some state explicitly that there is value in comparing and contrasting the situation in different places. In each of the thematic sections that follow the questions are highlighted through an initial presentation in a table, before we discuss and elaborate them.

Debating and visioning food from animals. Addressing the ways in which food from animals are framed, discussed and envisioned in different times and places falls squarely within the scope of the social sciences and humanities. Several different, albeit-related terms were mobilised during the question-setting around this theme including 'narrative', 'discourse', 'frame' and 'debate' each of which speak to different disciplinary traditions and theoretical perspectives. Nevertheless, all the terms share a concern with critically analysing ways of talking about, envisioning and imagining food from animals and the socio-material work that is realised through this talk (Table 2).

The first question (RQ1) calls for more attention to the ways in which societal debate around food from animals is emerging at different scales and across country contexts. One dimension of this debate concerns how different economic practices or models (e.g. based on de-growth) feature as more or less likely to support a move beyond animal-based food systems. Interest was also expressed in examining the variety of implications-political, economic, social, ethical-of the different positions expressed within these debates. A clear role was identified for social scientists by developing meaningful ways to foster further debate on food from animals. Successful examples of engagement and debate from other sectors should be identified. The question calls for further methodological development on dialogue and engagement, asking also what the appropriate level of engagement would be and for whom.
How, why and which stakeholders are contributing or not to the debates around animal-based foods was also identified as an important research question (RQ2). Politicians are one critical group of stakeholders whose engagement should be examined as well as their financial and other stakes in animal agriculture. Other key stakeholders include farmers, food and agriculture corporations, retailers and food co-ops, food activists and social movements in the Global North and South and, of course, consumers as eaters. The ethics and politics of stakeholder exclusions and inclusions was a further suggestion to be considered. The contribution of humanities research was underlined as being of value here, as this can foster recognition and understanding of the different cultural values behind hidden voices.

The participants highlighted that social sciences should also analyse future visions of food systems beyond their current animal-based character and how these future visions interact with other imagined future visions of sustainable food systems (RQ3). Bringing future visions into comparison should also entail analysing their different ethical implications together with their economic viabilities, social justice and environmental consequences, suggesting in turn the value of interdisciplinary research across the social sciences, humanities and natural sciences. The value of the arts in envisioning and speculating on alternative futures was recognised in this context.

Transforming agricultural spaces. The second research theme focuses upon the spaces of agriculture seeking to examine how moving beyond animal-based food systems involve their transformation. Agricultural spaces have been relatively neglected within social science and humanities research in this domain (Burton, 2019) with attention either more likely to be focused on questions of eating and consumption or innovations in the food industry such as the development and promotion of novel proteins (e.g. Sexton, 2018) (Table 3).

The questions begin by asking how existing members of agricultural and rural communities are responding to the debates about food from animals and specifically the calls to reduce their use (RQ4). Participants stressed the importance of cultural values and traditions, emotions and social justice as part of these investigations. This question links closely to RQ2 in recognising and addressing excluded stakeholders and voices. In anticipating negative consequences for agricultural and rural communities participants argued that research should address the means by

Table 2 Prioritised research questions (RQ) under the research theme 'Debating and visioning food from animals'.

\section{Research theme: Debating and visioning food from animals}

RQ1. What is the nature of societal debates around food from animals (political, economic, social, ethical)? How are these debates developing at different scales (international, national, regional, local) and in different country contexts, and how can further meaningful debate be fostered? RQ2. How and why do different stakeholders contribute to societal debates around food from animals and which stakeholders are excluded and why? RQ3. In what ways do future visions of reducing food from animals interact with other imagined future visions of sustainable food systems?

Table 3 Prioritised research questions under the research theme 'Transforming agricultural spaces'.

\section{Research theme: Transforming agricultural spaces}

RQ4. How and why are farmers and other rural community members responding to the calls for reducing food from animals?

RQ5. What are the behavioural, institutional, agronomic and economic challenges and opportunities associated with plant-based protein production and how do these compare across different geographical contexts?

RQ6. How, and by whom, are vegan agricultural systems being imagined and developed in different country contexts and what are the behavioural, institutional and economic barriers to and opportunities for their development? 
which these consequences could be mitigated. Another position suggested that better working conditions and employment opportunities might follow from a move beyond animal-based food systems particularly for those employed in the slaughtering and meat processing industries. This point takes on increased urgency during the current Covid-19 pandemic of 2020, because meat processing employees across Europe have been identified as a group particularly vulnerable to contracting the virus (van der Zee, 2020).

The next two questions seek to examine how agriculture might change either relatively more gradually, as existing or new plant protein crops are grown more widely within current agricultural structures, or in more radical ways, such as through the development of veganic agriculture. Addressing the multiple challenges and opportunities associated with plant protein production (RQ5) was identified as a programme level question that requires an interdisciplinary approach. This question incorporates the interest expressed by some participants in legumes and their actual and potential roles in transforming food systems, an issue that is not limited to the domain of agricultural production but raises several further questions relating to the creation of new value chains as well as to policy support and media attention. As one element of the wider interest in veganism, RQ6 focuses on vegan agriculture asking how, by whom, and where vegan agricultural systems are being imagined and developed and the various enablers and constraints.

Framing animals as food. The roles and meanings of animals in food systems were formulated as a separate research theme in which participants distinguished between studying the ways in which animals are understood and performed by various food system actors as well as by research and education. RQ7 'how do different food system actors understand and perform current and future roles of animals within the food system?' relates to RQ1 but directs attention to animals in their own right. Participants highlighted the need to better understand the future, present, but also past framings of animals as food in different food systems and cultures. As important as it is to understand current framings of animals as part of our food systems (and their variation across different cultural contexts), further historical studies are needed to understand how our food systems came to utilise animals as they do now and also whether lessons can be learned from the past replacement of animal labour in food systems (e.g. Fudge, 2018). The study of framing animals as food involves the recognition of the fact that these animals may impact framings by their own actions. They for instance can resist, disrupt or participate in co-construction. Including animals as agentic beings in social science and humanities research requires the development of research methods that are less human-centric-i.e. post-human - and more inclusive of the perspectives of others (e.g. Birke and Hockenhull, 2012; Despret, 2013) (Table 4).

The study of how animals are understood and performed in and by research (RQ8) should concentrate on elaborating how this takes place within different fields of science. To date, studies have concentrated largely on the use of animals in laboratory science (e.g. Greenhough and Roe, 2011; Mcleod and HobsonWest, 2016). As such, participants stressed the need to extend the focus to animal sciences, agriculture and economics, amongst other disciplines. It was also noted that how food animals are framed within different strands of social science and humanities research deserves its own critical reflection both in terms of disciplinary traditions and current research endeavours (e.g. Tuomivaara, 2019; Steiner, 2005). The latter is important given the longstanding humanistic and anthropocentric investments of the social sciences and humanities.

The forms and content of education about food animals were also highlighted as a specific research topic (RQ9) and builds on existing work in critical animal pedagogy (Gunnarsson and Pedersen, 2016). This was seen as important in building respect for animals and their treatment in research as well as in food production and consumption. The various levels of education were given attention here as well as the interaction between teachers and students in classroom practice.

Eating practices and identities. A great deal of attention was given to eating and consumption both in the formulation of research questions and in the workshop discussions. It was identified as a particularly important topic of research in moving beyond animal-based food systems even though participants recognised that there is already much research taking place on changes in meat-based and plant-based eating practices. The discussions, hence, concentrated on the identified gaps and future arrays of research. The participants insisted that it is vital to move away from behavioural, psychological and marketing-oriented consumer studies to include other social scientific understandings of eating practices (Shove, 2010; Warde, 2016) (Table 5).

The participants called for more attention to how different social and cultural groupings, identities (e.g. gender, ethnicity, religion, class, political orientation, age, education, income, area of residence) and their intersections play a role in (not) eating

Table 4 Prioritised research questions under the research theme 'Framing animals as food'.

\section{Research theme: Framing animals as food}

RQ7. How do different food system actors understand and perform current and future roles of animals within food systems, and how do these roles vary across different geographical contexts?

RQ8. How is the idea of a 'food animal' understood and performed within research across different academic disciplines?

RQ9. How are 'food animals' understood and performed in primary, secondary and tertiary education and what happens when these framings are discussed between teachers, pupils and students?

Table 5 Prioritised research questions under the research theme 'Eating practices and identities'.

\section{Research theme: Eating practices and identities}

RQ10. How do socio-economic categories and identities, and their intersections, play a role in (not) eating food from animals and the ways in which this form of eating is changing in practice?

RQ11. How, where and why is plant-based eating already being incorporated into daily food practices?

RQ12. What kinds of communities are meaningful, why, where and how, in supporting a reduction in the consumption of food from animals? 
Table 6 Prioritised research questions under the research theme 'Governing transitions beyond animal-based food systems'.

Research theme: Governing transitions beyond animal-based food systems

RQ13. What are the current agricultural policies and other public policies that support animal-based food systems, how are these policies legitimised and how do they need to change in order to support a shift towards more plant-based food systems?

RQ14. What is the actual and potential contribution of national dietary guidelines, public health and environmental behavioural change programmes, and public procurement to moving beyond animal-based food systems?

RQ15. How are local food partnerships in both urban and rural places contributing to the reduction of food from animals and what are the enabling and constraining conditions?

food from animals (RQ10) (Vinnari et al., 2010). The participants posed this question also as a self-reflection to their own disciplines: do the conventional sociological categories still play a role or should they be revisited? The participants underlined the specific need and value of a historical analysis of eating patterns across different socio-economic groups, regions and countries. The question on the role of food from animals in identity politics was posed as a specific question for political studies and sociological analysis.

The participants also argued that more research attention needs to be given to daily, ordinary eating practices and how, where and why plant-based eating is already being incorporated into these practices, whether by choice or necessity, and in both traditional and novel ways (RQ11). This speaks to the broader idea of 'normalisation' and 'routinisation' of novel practices so that they may be embedded in everyday life (e.g. Jallinoja et al., 2019; Mylan, 2018; Twine, 2018; Vainio et al., 2016). Research in this context should also consider the challenges and tensions in plant-based eating with respect to, e.g. household food (in) security, healthy eating, enjoyment/convivial eating, social relations and how these are reconciled. The study of everyday eating practices is seen as key to understanding how our eating can or will change as flexitarianism, reducitarianism or veganism become more prevalent. Here the participants saw cross-country comparisons of relevance. They called upon more collaboration amongst researchers in South, East and West to explore what can be learned from food cultures and cuisines in which protein-rich plant foods feature more prominently. The differences in Global North and South were also underlined with respect to nutritional challenges. Participants called for caution in drawing generalisations across cultures. Discussion of nutrition, as part of understanding changing eating patterns and practices, suggests a role for interdisciplinary research with nutrition scientists and epidemiologists.

RQ12 draws attention to communities and their role as change makers in reducing consumption of food from animals. For example, how could families, peer groups and other, potentially new communities (in work, recreational and other contexts), play a more prominent role in food system transitions? Food studies have conventionally examined the role of local communities in supporting more equal producer-consumer relations (Renting et al., 2012). In plant-based eating, however, new digital communities have gained more momentum, in particular amongst young people (e.g. Goodman et al., 2017; Lupton and Feldman, 2020; Lewis, 2020; Pohjolainen and Jokinen, 2020). How these various communities contribute to re-building our relation to food forms an important array of research. The role of educational communities both on and off-line was also recognised (RQ9).

Governing transitions beyond animal-based food systems. Alongside eating and consumption, the theme of 'Governing transitions beyond animal-based food systems' generated the largest number of questions in the initial stage of question setting. The research questions posed by the participants focused on the role of public policy interventions, with some recognition given to the role of the private sector and market-based governance mechanisms and less attention paid to civil society interventions. The scale of governance also varied, with some attention directed at national and international policy arrangements and in other cases at policies and strategies of specific (often public) institutions highlighting the complexity of the issue at stake (Table 6).

In order to contribute to thinking about the future policies and policy mixes, RQ13 recognises that there is now a need to critically revisit and evaluate how current public policies (including for instance agricultural and food, climate, health, economic development and trade) support animal-based food systems and-by extension-work against or do not equally support plant-based food systems. How these policies have been and continue to be legitimised is an important research question. The RQ13 is framed broadly in order to highlight the need for food systems analysis.

The current and future potential role of several more specific policy interventions in supporting plant-based eating and food systems are considered in RQ14. National nutrition guidelines, public procurement processes, public health and environment behaviour change programmes were all highlighted (Springmann et al., 2020). In the original list of research questions, the issue of carbon and meat taxes was also raised, but their evaluation was seen to be more of a task for economists. Instead, a meaningful question for social sciences was posed as follows: What role is left for the state in moving beyond animal-based food systems when taxation and other mechanisms designed to restrict the consumption of food from animals may face resistance from politicians who perceive such measures as vote losers (Goodland, 1997; Vinnari and Tapio, 2012)? Behaviour change programmes may be a preferred policy approach but these call for critical analysis.

In recent years, multi-sectoral partnerships have also been developed to support more sustainable food provisioning at scales other than the national. Food Policy Councils and the UK's Sustainable Food Cities network are two examples (Coulson and Sonnino, 2019). RQ15 directs attention to the potential of these multi-sectoral and multi-scale governance arrangements in supporting a reduction in the production and consumption of food from animals. Identifying the enabling and constraining conditions of this process will be an important dimension of this enquiry and should attend to the lead actors within food partnerships and the politics of this leadership, i.e. who gets to lead, from which sectors, why and with what implications?

The role of private sector governance was discussed in both workshops and highlighted the role of food manufacturers, retail and restaurants in guiding both food production and consumption (see also sections "Debating and visioning food from animals" and "Transforming agricultural spaces"). Their role in, for example, climate governance is understood to have increased as public policies, such as agricultural policies, have been slow to 
change. The participants called for better understanding of public and private governance-and their intersections-in supporting plant-based eating and food systems. They also argued that the implications for public policies of new forms of consumer creativity, criticality and taste around plant-based eating invites further investigation.

\section{Discussion and conclusion}

In this paper, we have described a research prioritisation process that was designed to develop capacity, mutual understanding and impact amongst researchers within the social sciences and humanities and to help coordinate research effort to address the societal grand challenge of moving beyond animal-based food systems. The process focused deliberately upon social sciences and humanities researchers in recognition of the more generally observed problem of selective openness to these disciplines within multi-discipline research programmes designed to address societal grand challenges (Morris et al., 2019). Organising the process in this way proved extremely worthwhile as it provided a dedicated space in which scholars had the freedom to identify collectively the most important research questions from their perspectives at a time when research funders are slowly beginning to acknowledge the need for research in this domain. Our experience suggests that the decision to focus the exercise on social scientists and humanities scholars successfully fostered an open and critical atmosphere which was important in bringing together scholars, many of whom had not worked together directly before and have different ideological commitments and disciplinary perspectives on the issue at stake. This openness was particularly crucial given the controversial nature of this topic even amongst social science and humanities scholars, let alone in other scientific and more public domains. The formation of new research relationships amongst the participants has found further expression in the writing of this article, invitations to workshops and seminars, and collaborations in the preparation of research funding applications. As such, the exercise has already begun to realise some of its stated objectives.

Out of an initial, long list of more than 100 research questions 15 have been prioritised and these constitute the key output of the process. This prioritised list was developed in iterative stages with different groups of researchers. The scope of the prioritised questions is considerable, moving from individuals to communities and institutions, from histories to futures and across multiple spatialities, with an emphasis both on systemic thinking and critical perspectives on power as these shape human-animal relations. The question list points towards the most pressing matters to which future research in the social sciences and humanities should devote its capacity and research effort. An additional outcome of the process has been the identification of a set of themes within which individual research questions can be positioned and promoted: (1) debating and visioning food from animals; (2) transforming agricultural spaces; (3) framing animals as food; (4) eating practices and identities; (5) governing transitions beyond animal-based food systems. These themes make connections between individual questions but also address both production and consumption in systems' change whilst strongly foregrounding animals as agents and stakeholders in these transformations. In this way they provide a guide to defining and shaping current and future research programmes or funding calls across a broad range of topics from the governance of climate change to the facilitation of sustainable food systems or more sustainable consumption. The themes and questions identified can also inform researchers from the natural sciences, social sciences and humanities, and stakeholders from beyond academia when developing, respectively, inter- and trans-disciplinary research collaborations to address these issues.

Importantly, the exercise led to a fundamental re-framing of the shared research area as investigating a movement "beyond animal-based food systems' rather than the initially proposed but deemed less accessible and more controversial framing of 'de-animalising food systems'. 'Moving towards plant-based food systems' is a further alternative framing that might be debated in future exercises. We therefore recommend including in future prioritisation exercises consideration of how the area of research enquiry is or could be framed or re-framed particularly when emergent and controversial research areas are being addressed and when there is a need to generate research capacity and momentum.

Although dietary change to more plant-based consumption has been identified as bringing several co-benefits to humans and nonhumans the concept of moving beyond animal-based food systems remains extremely provocative and challenging for researchers and research funders, for practitioners and decisionmakers within agri-food systems including but by no means limited to those communities whose livelihoods presently depend on 'food animals', and for consumers who continue to enjoy eating (often large quantities of) animal-based foods. The sensitivities of the issue were evident within our prioritisation exercise in the tensions amongst participants with regard to their different positions on animal-human relationships, specifically whether animals should continue to be used for food production or whether food systems need to move entirely beyond their use. One pragmatic approach to this ethical conundrum is to recognise that a dimensionality of positions and pathways exist within this research area. Another is to ensure that the tension itself becomes a research object and the focus of future research questions.

That the research area is characterised by such challenges also points to the importance and urgency of extending the research prioritisation exercise to engage a wider constituency of interested actors both within and beyond research institutions. This could usefully include scholars from social sciences and humanities disciplines that were underrepresented in our exercise including those from outside Europe, as well as those from-amongst others-the arts, health, nutrition, animal and veterinary sciences, epidemiology and economics. Arguably, animals themselves should also be a part of future prioritisation exercises although how their representation is realised requires further careful and creative consideration in the spirit of more experimental non-human scholarship (Hamilton and Taylor, 2017). Engaging a wider group of actors in future research agenda-setting exercises will also support the development of both interdisciplinary and transdisciplinary research into moving beyond animal-based food systems. However, this is not a blanket recommendation. As Morris et al. (2019) argue inter/ trans-disciplinarity should always be approached critically even though this challenges dominant research governance discourses which naturalise these ways of producing knowledge. Whether the reframing of the topic as described here is suitable for the purposes of engaging a wider group of participants, or whether an alternative, less obviously contentious framing is needed is another matter to which the designers of future prioritisation exercises will need to pay close attention.

\section{Data availability}

All data generated or analysed during this study are included in this published article. 
Received: 26 March 2020; Accepted: 22 December 2020;

Published online: 03 February 2021

\section{Notes}

1 We use the term 'animal' to refer to land-based animals farmed for their food products, e.g. cows, sheep, pigs, chickens, goats. Although humans are also animals, most people do not eat human animals or human animal products. As such, for the sake of simplicity and readability rather than use the term 'non-human animal', which more accurately expresses our constituencies of concern, we use the term animal throughout the paper.

2 In these programmes the question of animal-based food systems tends not to be approached directly, but rather as a reference to other sustainability problems.

3 We discuss further this framing and its limitations (which lead us to adopt an alternative framing for the purposes of reporting) in the section "Defining an emerging area of research interest".

4 Four of the participants at the second workshop had also participated in the first workshop, a figure that includes the two lead researchers.

5 This distinction is made deliberately in recognition of the fact that, as expressed by one participant, "the food system is only one part of a wider vegan project [although] it is essential to it and the most significant field of violence".

\section{References}

Aavik K (2019a) The rise of veganism in post-socialist Europe: making sense of emergent vegan practices and identities in Estonia. In: Wright L (ed) Through a vegan studies lens: textual ethics and lived activism. University of Nevada Press, Nevada, pp. 146-164

Aavik K (2019b) Institutional resistance to veganism: constructing vegan bodies as deviant in medical encounters in Estonia. Health 3:1-18

Akerlof K, Tyler C, Foxen S et al. (2019) A collaboratively derived international research agenda on legislative science advice. Palgrave Commun 5:108-121

Allievi F, Vinnari M, Luukkanen J (2015) Meat consumption and productionanalysis of efficiency, sufficiency and consistency of global trends. J Clean Prod 92(1):142-151

Almiron N (2016) The political economy behind the oppression of other animals: Interest and influence. In: Almiron N, Cole M, Freeman C (eds) Critical animal and media studies: communication for nonhuman animal advocacy. Routledge, New York, pp. 26-41

de Bakker E, Dagevos H (2012) Reducing meat consumption in today's consumer society: questioning the citizen-consumer gap. J Agric Environ Ethics 25:877-894

Balmer A, Calvert J, Marris C et al. (2015) Taking roles in interdisciplinary collaborations: reflections on working in post-ELSI spaces in the UK synthetic biology community. Sci Technol Stud 28(3):3-25

Beardsworth A, Keil T (1992) The vegetarian option: varieties, conversions, motives and careers. Sociol Rev 40:253-93

Birke L, Hockenhull J (2012) Crossing boundaries: investigating human-animal relationships. Koninklijke Brill NV, Leiden

Bjørkdahl K, Syse K (2016) Taming time, timing death. Routledge, London

Brown S (2019) What's the beef? Conflicting recommendations for meat and cancer risk. World Cancer Research Fund International. https://www.wcrf. org Accessed 23 Jan 2020

Burton R (2019) The potential impact of synthetic animal protein on livestock production: the new "war against agriculture"? J Rural Stud 68:33-45

Castree N, Adams J, Barry N et al. (2014) Changing the intellectual climate. Nat Clim Change 4(9):763-768

Chiles R (2016) Hidden in plain sight: how industry, mass media, and consumers' everyday habits suppress food controversies. Sociol Rural 57:791-815

Cole M, Morgan K (2011) Vegaphobia: derogatory discourses of veganism and the reproduction of speciesism in UK national newspapers. Br J Sociol 62:134-53

Cole M, Stewart K (2014) Our children and other animals: the cultural construction of human-animal relations in childhood. Ashgate, Aldershot

Coulson H, Sonnino R (2019) Re-scaling the politics of food: place-based urban food governance in the UK. Geoforum 98: 170-179

Davies GF, Greenhough BJ, Hobson-West P, Kirk RGW, Applebee K, Bellingan LC, et al. (2016) Developing a collaborative agenda for humanities and social scientific research on laboratory animal science and welfare. PLoS ONE 11 (7):e0158791

de Boer J, Schösler H, Aiking H (2014) 'Meatless days' or 'Less but better'? Exploring strategies to adapt western meat consumption to health and sustainability challenges. Appetite 76:120-128

de Boer J, Schösler H, Aiking H (2017) Towards a reduced meat diet: mindset and motivation of young vegetarians, low, medium and high meat-eaters. Appetite 113:387-397
Despret V (2013) From secret agents to interagency. Hist Theory 52:29-44

Doyle J (2016) Celebrity vegans and the lifestyling of ethical consumption. Environ Commun 10:777-90

Driessen C, Korthals M (2012) Pig towers and in vitro meat: disclosing moral worlds by design. Soc Stud Sci 42(6):797-820

Efstathiou S (2016) Is it possible to give scientific solutions to Grand Challenges? On the idea of grand challenges for life science research. Stud Hist Philos Sci Pt C56:48-61

Efstathiou S, Korsnes M, Gabrielsen AM, Finstad T, Giæver F, Driessen C, Wethal $\mathrm{U}$ (2019) Investigating the elasticity of meat consumption for climate mitigation: 4Rs for responsible meat use. In: Vinnari E, Vinnari M (eds) Sustainable governance and management of food systems: ethical perspectives. Wageningen Academic Publishers, Wageningen, pp. 447-492

Elzerman J, Hoek A, van Boekel M, Luning P (2011) Consumer acceptance and appropriateness of meat substitutes in a meal context. Food Qual Preference 22:233-40

Emel J, Neo H (2015) Political ecologies of meat. Routledge, London

EC, European Commission (2020) A Farm to Fork Strategy for a fair, healthy and environmentally-friendly food system. Communication from the Commission to the European Parliament, the European Council, The Council, The European Economic and Social Committee and the Committee of Regions. $\operatorname{COM}(2020) 381$ final. https://ec.europa. Accessed 23 Jun 2020

FAO, Food and Agriculture Organization (2018) Sustainable food systems-concept and framework. Briefs. http://www.fao.org. Accessed 23 Jun 2020

Felt U (2014) Within, across and beyond: reconsidering the role of social sciences and humanities in Europe. Sci Cult 23(3):384-396

Fiddes N (1994) Social aspects of meat eating. Proc Nutr Soc 53: 271-280

Fitzgerald A, Taylor N (2015) The cultural hegemony of meat and the animal industrial complex. In: Taylor N, Twine R (eds) The rise of critical animal studies: from margin to centre. Routledge, New York and London

Fourat E, Lepiller O (2017) Forms of food transition: sociocultural factors limiting the diets' animalisation in France and India. Sociol Rural 57:41-63

Fudge E (2018) Quick cattle and dying wishes: people and their animals in early modern England. Cornell University Press, Ithaca

Garnett T, Mathewson S, Angelides P, Borthwick F (2015) Policies and actions to shift eating patterns: what works? A review of the evidence of the effectiveness of interventions aimed at shifting diets in more sustainable and healthy directions. Food Climate Research Network, Chatham House, The Royal Institute of International affairs, London

Godfray H, Aveyard P, Garnett T, Hall J, Key T, Lorimer J, Pierrehumbert R, Scarborough P, Jebb J (2018) Meat consumption, health and the environment. Science 361:6399

Goodland R (1997) Environmental sustainability in agriculture: diet matters. Ecol Econ 23(3):189-200

Goodman M, Johnston J, Cairns K (2017) Food, media and space: the mediated biopolitics of eating. Geoforum 84:161-168

Greenebaum J, Dexter B (2018) Vegan men and hybrid masculinity. J Gend Stud 27:637-48

Greenhough B, Roe E (2011) Ethics, space and somatic sensibilities: comparing relationships between scientific researchers and their human and animal experimental subjects. Environ Plan D 29:47-66

Greenhough B et al. (2020) Setting the agenda for social science research on the human microbiome. Palgrave Commun 6:18

Gunnarsson D, Pedersen H (2016) Critical animal pedagogies: re-learning our relations with animal others. In: Lees $\mathrm{H}$, Noddings $\mathrm{N}$ (eds) The Palgrave International handbook of alternative education. Palgrave Macmillan, London, p 415-430

Hamilton L, Taylor N (2017) Ethnography after humanism: power, politics and method in multi-species research. Palgrave McMillan, London

Hansen A, Jakobsen J (2020) Meatification and everyday geographies of consumption in Vietnam and China. Geogr Ann: Ser B102(1):21-39

Haraway D (1988) Situated knowledges: the science question in feminism and the privilege of partial perspective. Fem Stud 14(3):575-599

Hasson F, Keeney S, McKenna H (2000) Journal of Advanced Nursing 32 (4):1008-1015

High Level Panel of Experts (2017) Nutrition and food systems. A report by the High-Level Panel of Experts on Food Security and Nutrition of the Committee on World Food Security, Rome

Hoek A, Luning A, Stafleu A, de Graaf C (2004) Food-related lifestyle and health attitudes of Dutch vegetarians, non-vegetarian consumers of meat substitutes, and meat consumers. Appetite 42:265-72

Ingram J, Wright $\mathrm{H}$, Foster L et al. (2013) Priority questions for the UK food system. Food Secur 5:617-636

Intergovernmental Panel on Climate Change (2019) Climate change and land: summary for policymakers. Accessed 1 Mar $2020 \mathrm{https} / / / w w w . i p c c . c h / s r c c l /$

International Panel of Experts on Sustainable Food Systems (2015) The new science of sustainable food systems: overcoming barriers to food system reform. International Panel of Experts on Sustainable Food Systems 
Jallinoja P, Vinnari M, Niva M (2019) Veganism and plant-based eating: analysis of interplay between discursive strategies and lifestyle political consumerism. In: Boström M, Micheletti M, Oosterveer P (eds) The Oxford handbook of political consumerism. Oxford University Press, Oxford Press, pp. 157-179

James Lind Alliance (2000) James Lind Alliance Guidebook. Version 9 March 2020. Available online: www.jla.nihr.ac.uk

Kaljonen M, Peltola T, Salo M, Furman E (2019) Attentive, speculative experimental research for sustainability transitions: an exploration in sustainable eating. J Clean Prod 206:365-373

Kaljonen M, Salo M, Lyytimäki J, Furman E (2020) From isolated labels and nudges to sustained tinkering: assessing long-term changes in sustainable eating at a lunch restaurant. Br Food J 122:3313-3329

Kuhlmann S, Rip A (2014) The challenge of addressing Grand Challenges. A think piece on how innovation can be driven towards the "Grand Challenges" as defined under the prospective European Union Framework Programme Horizon 2020. Report to ERIAB. European Commission, Brussels

Kuhlmann S, Rip A (2018) Next-generation innovation policy and grand challenges. Sci Public Policy 45(4):448-454

Laestadius L, Neff R, Barry C, Frattaroli S (2014) 'We don't tell people what to do': an examination of the factors influencing NGO decisions to campaign for reduced meat consumption in light of climate change. Global Environ Change 29:32-40

Lewis T (2020) Digital food: from paddock to platform. Bloomsbury, London

Lonkila A, Kaljonen M (2021) Promises of meat and milk alternatives for sustainable food system transitions-integrative literature review on emergent research themes. Agric Hum Values (in press)

Lupton D, Feldman Z (2020) Digital food cultures. Routledge, London

McLeod C, Hobson-West P (2016) Opening up animal research and sciencesociety relations? A thematic analysis of transparency discourses in the UK. Public Underst Sci 25:791-806

Morris C, Kirwan J (2006) Vegetarians: uninvited, uncomfortable or special guests at the table of the alternative food economy? Sociol Rural 46:192-213

Morris C, Kirwan J, Lally R (2014) Less Meat Initiatives: an initial exploration of a diet-focused social innovation in transitions to a more sustainable regime of meat provisioning. Int J Sociol Agric Food 21:189-208

Morris C (2019) 'Taking the politics out of broccoli': debating (De)meatification in UK national and regional newspaper coverage of the Meat Free Mondays campaign. Sociol Rural 58:433-452

Morris C, Raman S, Seymour S (2019) Openness to social science knowledges? The politics of disciplinary collaboration within the field of UK food security research. Sociol Rural 59:23-43

Mylan J (2018) Sustainable consumption in everyday life: a qualitative study of UK consumer experiences of meat reduction. Sustainability 10:1-13

Mylan J, Morris C, Beech E, Geels F (2019) Rage against the regime: niche-regime interactions in the societal embedding of plant-based milk. Environ Innov Soc Transit 31:233-47

Nibert D (2016) Origins of oppression, specialist ideology, and the mass media. In: Almiron N, Cole M, Freeman C (eds) Critical animal and media studies: communication for nonhuman animal advocacy. Routledge, New York, pp. 74-88

O'Neill J (2015) Antimicrobials in agriculture and the environment: reducing unnecessary use and waste. Review on antimicrobial resistance. Welcome Trust and HM Government, London

Petticrew M, Roberts H (2006) Systematic reviews in the social sciences: a practical guide. Wiley-Blackwell, Malden

Pohjolainen P, Jokinen P (2020) Meat reduction practices in the context of a social media grassroots experiment campaign. Sustainability 12(9):3822

Potts A (ed) (2016) Meat culture. Brill, Leiden

Potts A, Parry J (2010) Vegan sexuality: challenging heteronormative masculinity through meat-free sex. Fem Psychol 20(1):53-72

Pretty J, Sutherland W, Ashby J et al. (2010) The top 100 questions of importance to the future of global agriculture. Int J Agric Sustain 8(4):219-236

Renting H, Schermer M, Rossi A (2012) Building food democracy: exploring civic food networks and newly emerging forms of food citizenship. Int J Sociol Agric Food 19:289-307

Rosenfeld D, Burrow A (2017) Vegetarian on purpose: understanding the motivations of plant-based dieters. Appetite 116:456-63

Ruby M (2011) Vegetarianism: a blossoming field of study. Appetite 58:141-50

Sandoe P, Nielsen B, Christensen L, Sorensen P (1999) Staying good while playing God: the ethics of breeding farm animals. Animal Welf 8:313-328

Schot J, Steinmueller W (2016) Framing innovation policy for transformative change: innovation policy 3.0. SPRU working paper series, Brighton.

Sexton A, Garnett T, Lorimer J (2019) Framing the future of food: the contested promises of alternative proteins. Environ Plan E 2:47-72

Sexton A (2018) Eating for the post-Anthropocene: alternative proteins and the biopolitics of edibility. Trans Inst Br Geogr 43:586-600

Shove E (2010) Beyond the ABC: climate change policy and theories of social change. Environ Plan A 42:1273-1285
Shove E, Pantzar M, Watson M (2012) The dynamics of social practice: everyday life and how it changes. Sage, London

Singer R (2016) Neoliberal backgrounding, the Meatless Monday campaign, and the rhetorical intersections of food, nature, and cultural Identity. Commun Cult Critique 10:2

Smart A (2004) Adrift in the mainstream: challenges facing the UK vegetarian movement. Br Food J 106:79-92

Springmann M, Clark M, Mason-D'Croz D et al. (2018) Options for keeping the food system within environmental limits. Nature 562:519-525

Springmann M, Spajic L, Clark M, Poore J, Herforth A, Webb P, Rayner M, Scarborough P (2020) The healthiness and sustainability of national and global food based dietary guidelines: modelling study. Br Med J 370:m2322

Steiner G (2005) Anthropocentrism and its discontents: the moral status of animals in the history of western philosophy. University of Pittsburgh Press, Pittsburgh

Stephens N, Sexton A, Driessen C (2019) Making sense of making meat: key moments in the first 20 years of tissue engineering muscle to make food. Front Sustain Food Syst 3:45

Sutherland W, Adams W, Aronson R et al. (2009) One hundred questions of importance to the conservation of global biological diversity. Conserv Biol J 23:557-567

Sutherland W, Fleischman E, Mascia M et al. (2011) Methods for collaboratively identifying research priorities and emerging issues in science and policy. Methods Ecol Evol2:238-247

Sutherland WJ, Bellingan L, Bellingham J et al. (2012) A collaboratively-derived science-policy research agenda. PLoS ONE 7(3):e31824

Swinburn B, Kraak S et al. (2019) The global syndemic of obesity, undernutrition, and climate change: The Lancet Commission report. Lancet 393:791-846

Tuomivaara S (2019) Animals in the sociologies of Westermarck and Durkheim. Palgrave Macmillan, London

Twine, R. (2010) Animals as Biotechnology - Ethics, Sustainability and Critical Animal Studies. London: Routledge

Twine R (2014) Vegan killjoys at the table-contesting happiness and negotiating relationships with food practices. Societies 4:623-39

Twine R (2018) Materially constituting a sustainable food transition: the case of vegan eating practice. Sociology 52:166-181

Vainio A, Niva M, Jallinoja P, Latvala T (2016) From beef to beans: eating motives and the replacement of animal proteins with plant proteins among Finnish consumers. Appetite 106:92-100

van der Zee B (2020) Poor conditions in meat plants fuel Covid-19 outbreaks, say unions. The Guardian Online, 22 June 2020. Accessed 29 Jun 2020

Vialles N (1994) Animal to edible. Cambridge University Press, Cambridge

Vinnari M, Tapio P (2009) Future images of meat consumption in 2030. Futures 41 (5):269-278

Vinnari M, Tapio P (2012) Sustainability of diets: from concepts to governance. Ecol Econ 74:46-53

Vinnari M, Mustonen P, Räsänen P (2010) Tracking down trends in non-meat consumption in Finnish households, 1966-2006. Br Food J 112(8):836-852

Vinnari M, Vinnari E (2014) A framework for sustainability transition: the case of plant-based diets. J Agric Environ Ethics 27:369-396

Warde A (2016) The practice of eating. Polity Press, Cambridge

Weis T (2007) The global food economy: the battle for the future of farming. Zed Books, London

Weis T (2013) The ecological hoofprint: the global burden of industrial livestock. Zed Books, London

Weis T (2015) Meatification and the madness of the doubling narrative. Can Food Stud 2:296-303

Willett W, Rockström J, Loken B et al. (2019) Food in the Anthropocene: the EAT-Lancet Commission on healthy diets from sustainable food systems. Lancet 393:447-492

Winders W, Ransom E (2019) Global meat: social and environmental consequences of the expanding meat industry. MIT Press, Cambridge

\section{Acknowledgements}

This work was supported by the British Academy (grant number: SG170396), Academy of Finland (grant number: 296884) and the InSPIRES project of the European Union's Horizon 2020 research and innovation programme (grant agreement number 741677, https://inspiresproject.com/). We are grateful also to the following researchers who contributed to one or more stages of the research prioritisation process reported in the article: Donald Bruce, Teea Kortetmäki, Kate Millar, Maria Saari, Alex Sexton, Rachel Tarlinton, Rhoda Wilkie.

\section{Author contributions}

All contributing authors confirm they satisfy the journal's criteria for authorship. 


\section{Competing interests}

The authors declare no competing interests.

\section{Additional information}

Correspondence and requests for materials should be addressed to C.M.

Reprints and permission information is available at http://www.nature.com/reprints

Publisher's note Springer Nature remains neutral with regard to jurisdictional claims in published maps and institutional affiliations. (c) (i) Open Access This article is licensed under a Creative Commons Attribution 4.0 International License, which permits use, sharing, adaptation, distribution and reproduction in any medium or format, as long as you give appropriate credit to the original author(s) and the source, provide a link to the Creative Commons license, and indicate if changes were made. The images or other third party material in this article are included in the article's Creative Commons license, unless indicated otherwise in a credit line to the material. If material is not included in the article's Creative Commons license and your intended use is not permitted by statutory regulation or exceeds the permitted use, you will need to obtain permission directly from the copyright holder. To view a copy of this license, visit http://creativecommons.org/ licenses/by/4.0/.

(c) The Author(s) 2021, corrected publication 2022

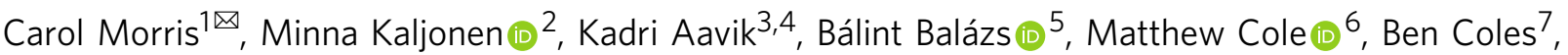
Sophia Efstathiou ${ }^{8}$, Tracey Fallon ${ }^{9}$, Mike Foden ${ }^{10}$, Eva Haifa Giraud ${ }^{11}$, Mike Goodman ${ }^{12}$, Eleanor Hadley Kershaw (10 ${ }^{1}$, Richard Helliwell ${ }^{13}$, Pru Hobson-West ${ }^{1}$, Matti Häyry ${ }^{14}$, Piia Jallinoja ${ }^{15}$, Mat Jones ${ }^{16}$, Taija Kaarlenkaski ${ }^{17}$, Maarit Laihonen ${ }^{14}$, Anu Lähteenmäki-Uutela ${ }^{2}$, Saara Kupsala ${ }^{18}$, Annika Lonkila ${ }^{2}$, Lydia Martens ${ }^{11}$, Renelle McGlacken ${ }^{1}$, Josephine Mylan ${ }^{19}$, Mari Niva ${ }^{3}$, Emma Roe $^{20}$, Richard Twine ${ }^{21}$, Markus Vinnari ${ }^{3} \&$ Richard White 22

${ }^{1}$ University of Nottingham, Nottingham, UK. ${ }^{2}$ Finnish Environment Institute, Helsinki, Finland. ${ }^{3}$ University of Helsinki, Helsinki, Finland. ${ }^{4}$ Tallinn University, Tallinn, Estonia. ${ }^{5}$ Environmental Social Science Research Group, Budapest, Hungary. ${ }^{6}$ Open University, Milton Keynes, UK. ${ }^{7}$ University of Leicester, Leicester, UK. ${ }^{8}$ Norges teknisk-naturvitenskapelige universitet, Trondheim, Norway. ${ }^{9}$ University of Nottingham, Ningbo, China. ${ }^{10}$ University of Sheffield, Sheffield, UK. ${ }^{11}$ Keele University, Keele, UK. ${ }^{12}$ Reading University, Reading, UK. ${ }^{13}$ Ruralis, Trondheim, Norway. ${ }^{14}$ Aalto University, Espoo, Finland. ${ }^{15}$ University of Tampere, Tampere, Finland. ${ }^{16}$ University of West of England, Bristol, UK. ${ }^{17}$ University of Turku, Turku, Finland. ${ }^{18}$ Finnish Food Authority, Helsinki, Finland. ${ }^{19}$ University of Manchester, Manchester, UK. ${ }^{20}$ University of Southampton, Southampton, UK.

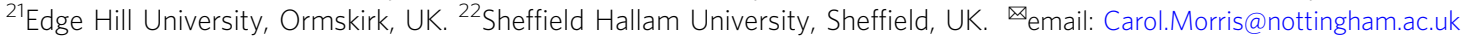

